\title{
Apexification Using MTA : A Challenging Approach
}

\author{
Dr.Tanu Mahajan *, Dr.Rohit Kochhar ${ }^{* *}$, Dr.Manju Kumari ${ }^{* * * *}$ \\ * M.D.S. 3RD Year student, Department of Conservative Dentistry and Endodontics, ITS Dental College,Hospital\& Research Centre, Greater Noida \\ Delhi NCR, \\ ** B.D.S.,M.D.S. H.O.D. Department of conservative and endodontics ITS Dental College,Hospital\& Research Centre, Greater Noida, Delhi NCR \\ ${ }^{* * * *}$ B.D.S. , M.D.S., Professor Department of Conservative Dentistry and Endodontics, ITS Dental College,Hospital\& Research Centre ,Greater \\ Noida, Delhi NCR
}

DOI: $10.29322 / I J S R P .10 .02 .2020 . p 9828$

http://dx.doi.org/10.29322/IJSRP.10.02.2020.p9828

\begin{abstract}
It is always a challenge to conserve a non vital tooth with immature root due to open root apices. Apexification is a method which induces a calcific barrier at the apex of a nonvital tooth with open apices.1Mineral trioxide aggregate [MTA] is an inert filling material and that is why it makes a perfect seal at the apex.Apexification treatment is supposed to create an environment that permits the deposition of cementum,periodontal ligament and even bone in a non vital pulp tooth. Frank has described four successful results of Apexification and that are continued closure of the canal and apex to a normal appearance, a dome shaped apical closure with the canal retaining a blunderbuss appearance, no apparent radiographic change but a positive stop in the apical area or a positive stop and radiographic evidence of a barrier coronal to the apex of the tooth.
\end{abstract}

Index Terms- Apexification; Open apices; Mineral Trioxide Aggregate; Blunderbuss canal.

\section{INTRODUCTION}

$\mathrm{T}$ The apex closure during the root development is last to occur and it takes a minimum of 3-4 years after the tooth eruption leading to 'Open Apices'[Figure 1]. Cvek's classification definesthe maturity of the unerupted incisors ${ }^{3}$. In Group 1 the teeth with wide,divergent root end and root to be less than half the final length.In Group 2, the teeth with roots between one half and two thirds of the final root length are included. In Group 3, the teeth with roots two third of their final root length, In Group 4, the teeth with open apical foramina and full root length and those with completed root length are included in Group 5. Trauma and Caries are regarded as the frequent causes of pulpal necrosis and open apices in young immature permanent teeth as it stops further root development. ${ }^{1}$ The endodontic treatment of a necrosed pulp with an open apex tooth has always been a challenge for dentists due to presence of thin fragile dentinal walls,reduced root lengths and a wide apex which do not allow the conventional fillingtechniques. Apexification with calcium hydroxide has been the treatment of choice in previous years. As it has many limitations like long time span of the treatment, requires many appointments, increased clinical costs and long term usage of calcium hydroxide weakens the dentinal walls making it prone to fractures ${ }^{6}$.These shortcomings are taken care by the use of MTA [mineral trioxide aggregate ] in place of calcium hydroxide. When MTA is used for apexification, it is done in a single visit and it produces more favourable results ${ }^{4}$.It also demonstrated a better biocompatibility, antibacterial properties, less setting time and good sealing ability.Therefore the purpose of this article is to emphasize the single appointment Apexification using (mineral trioxide aggregate) MTA. 


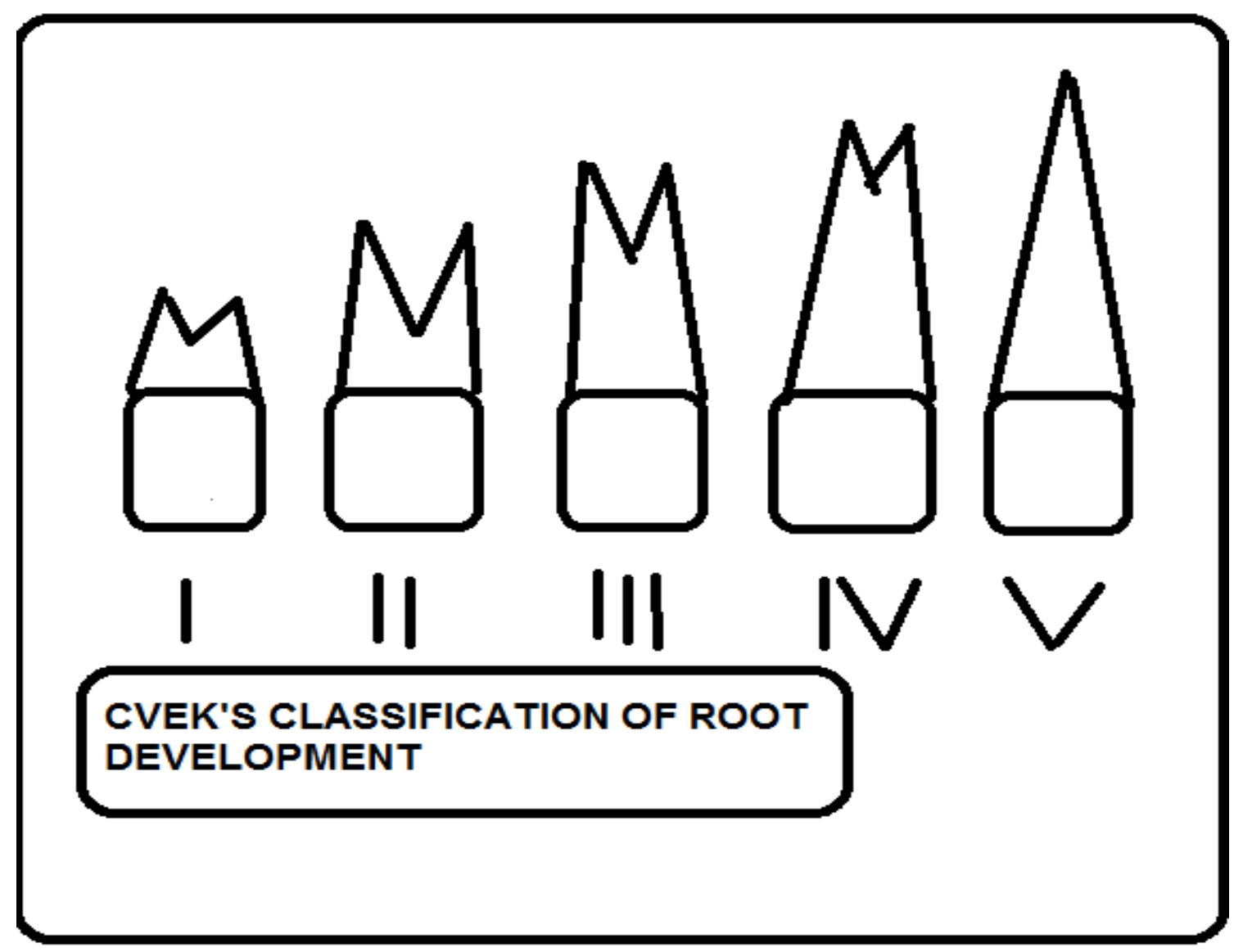

[Figure 1]. 


\section{Case History:}

\section{CASE 1:}

A 20 year old male patient reported in the Department of Conservative Dentistry and Endodontics with chief complaint of discolouration of right maxillary central incisor tooth. He had a history of RCT done w.r.t. 11 following a trauma 1 year back. The extraoral examination was normal. The pulp vitality tests - cold test, thermal test and electric test were negative. On radiographic examination the root canal was small and filled with Gutta Percha with an Open Apex[Figure 2]. Apexification using MTA was planned. Gutta Percha was removed w.r.t. 11 [Figure 3] and working length was determined $(23 \mathrm{~mm})$.[Figure 4] The canal was irrigated with $2.5 \% \mathrm{NaOCl}$ and was dried with paper points and root canal dressing with calcium hydroxide was given after cleaning and shaping of the canal. The patient was recalled after a week and in the second visit colla plug was inserted at the apical portion(open) of the canal followed byMTA as apical barrier with the help of pluggers for a thickness of $5 \mathrm{~mm}$ [Figure 5]. A wet cotton pellet was placed over the MTA in the canal and atemporary dressing was given.In next appointment obturation was done with Gutta Percha using lateral condensation technique followed by post Endodontic restoration with composite. Tooth was prepared and Crown insertion is done. Patient is being followed up after 6 months[Figure6]. 


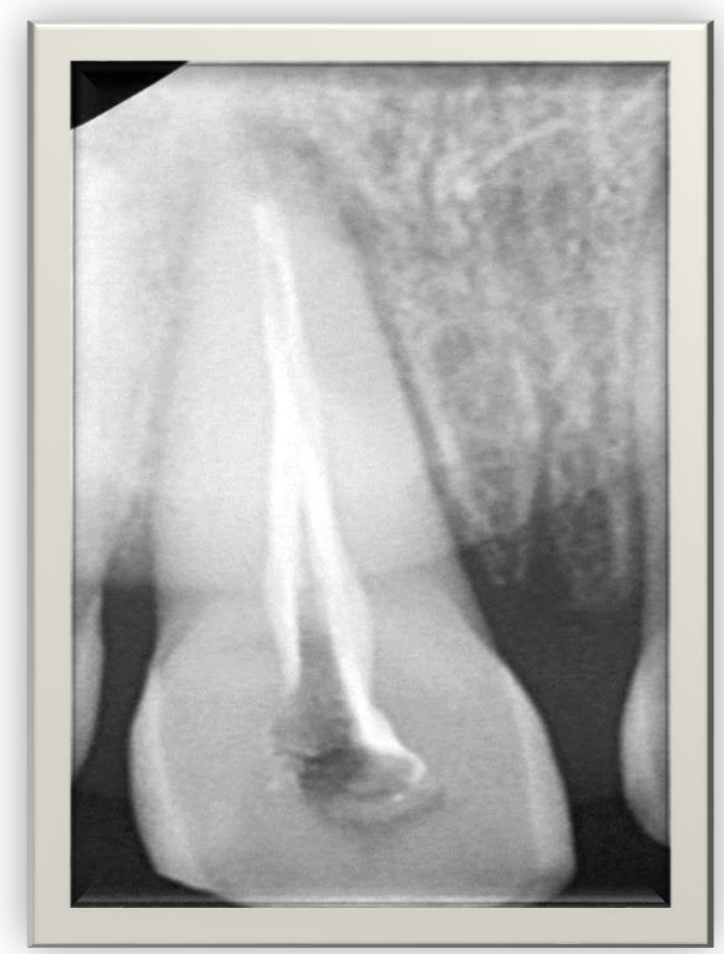

\section{FIG} 2:PREOPERATIVERADIOGRAP 


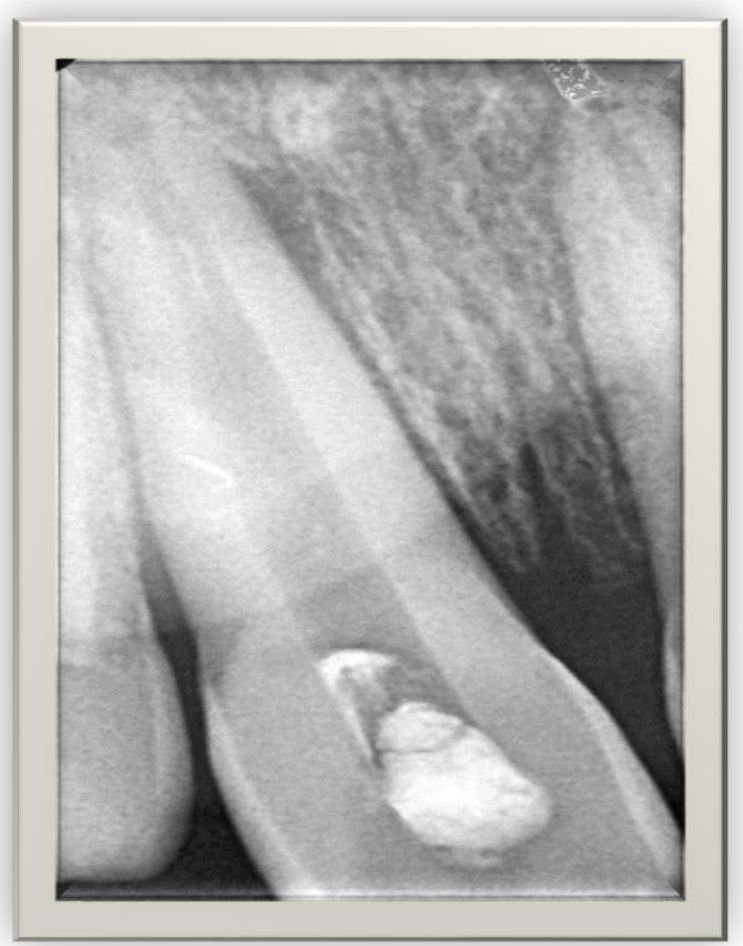

FIG 3: GUTTA PERCHA REMOVAL WAS DONE 


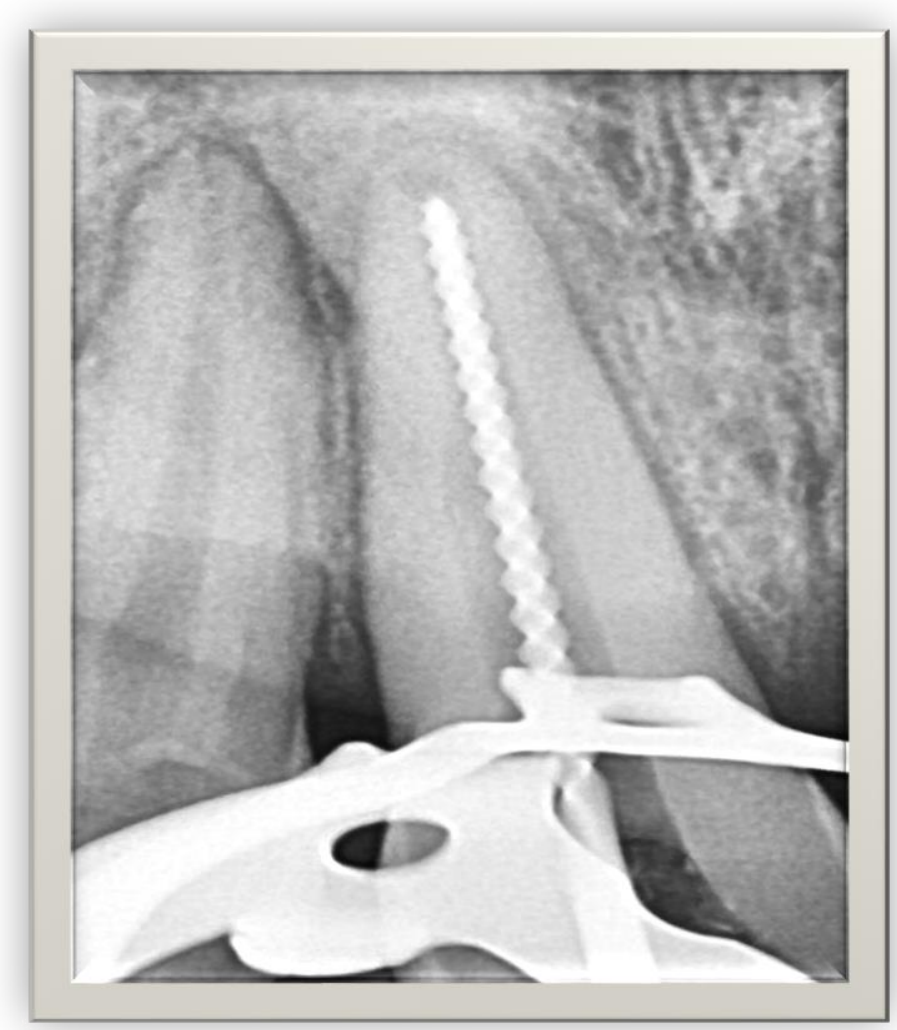

FIG 4: WORKING LENGTH DETERMINED 


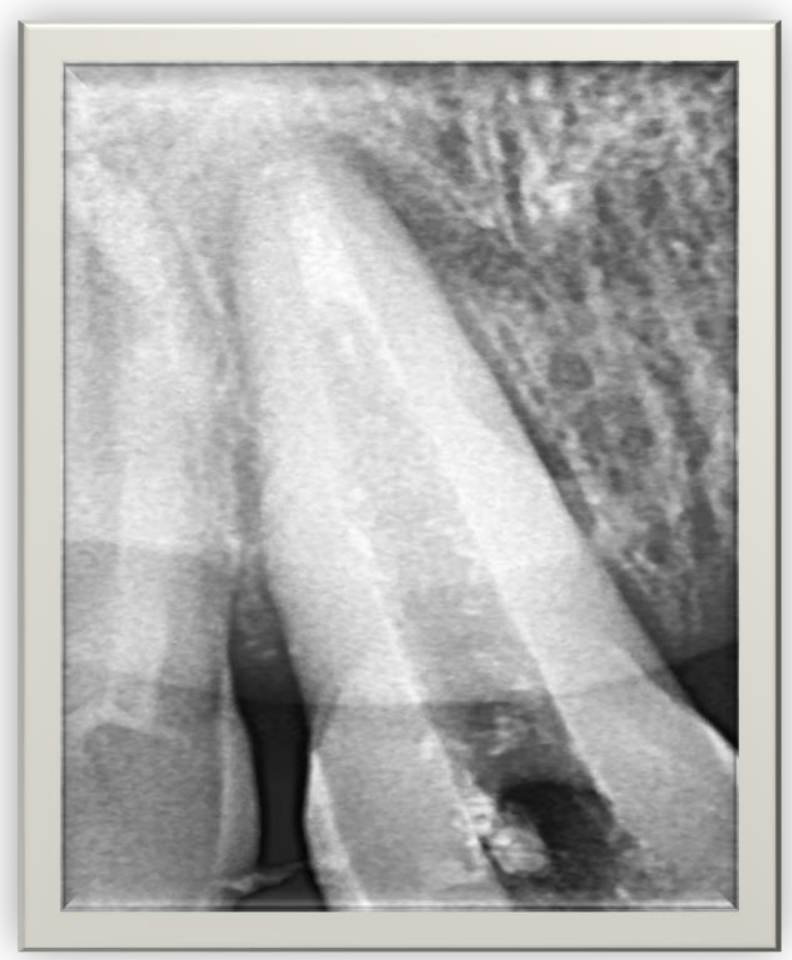

FIG 5: MTA PLUG FORMATION 


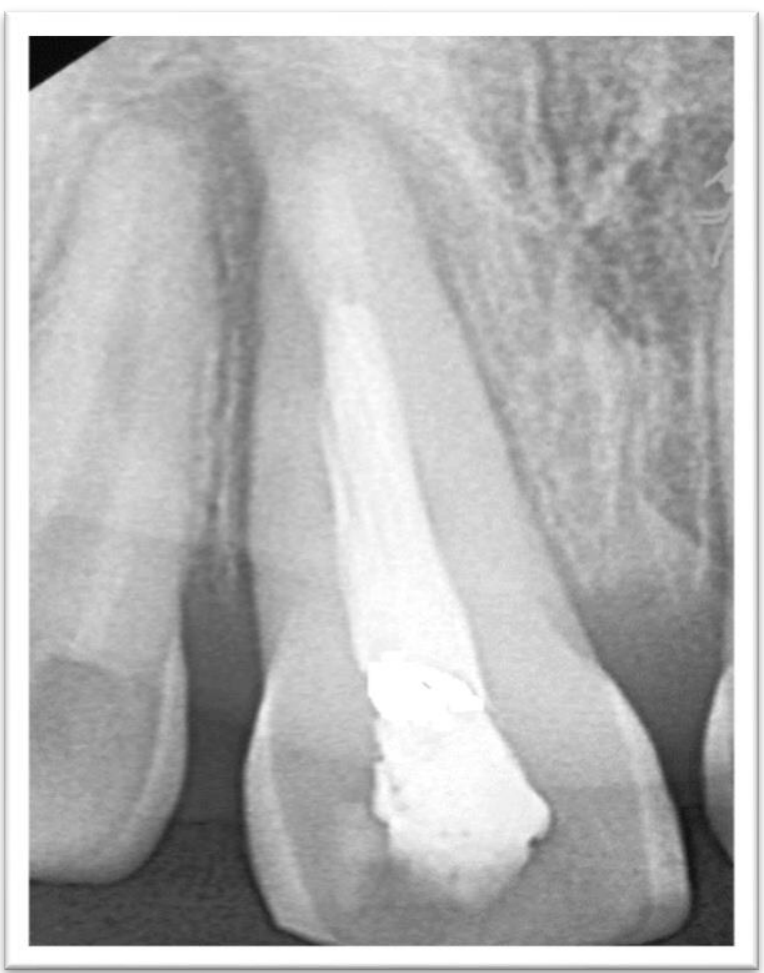

\section{FIG 6: OBTURATION AND POST ENDODONTIC RESTORATION DONE}




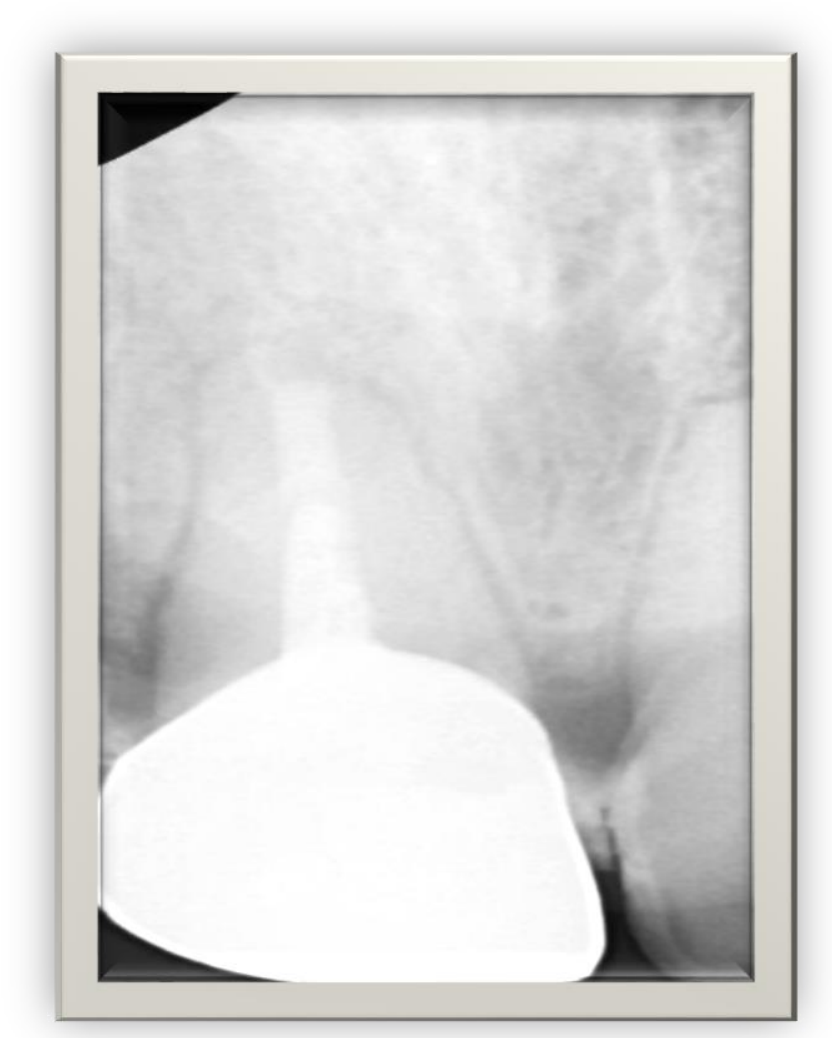

\section{FIG 7: FOLLOWUP AFTER 6 MONTHS}

\section{CASE REPORT 2 :}

A 21 year old male patient reported in the outdoor clinic in the Department of Conservative Dentistry and Endodontics with the complaint of a decayed tooth in upper front tooth region since 1 year.A detailed extra-oral and intra-oral examination was done. The pulp vitality tests were done- where Cold test,Thermal test and electric test came negative indicating Pulpal Necrosis. On Radiographic examination,there was root resorption in relation to maxillary left central and lateral incisor[Figure 1].For this patient a non surgical root canal treatment followed by a MTA apical plug was planned

The access opening was done and the working length was determined [22mm]( FIGURE 2). Biomechanical prepration was done using conventional method by 80 size $\mathrm{K}$ file with circumferential motion. Root canal debridement was done by irrigation using $2.5 \%$ sodium hypochlorite (31 gauge needle) and saline alternatively.Root canal was dried and root canal dressing was given by Calcium hydroxide $\left[\mathrm{Ca}(\mathrm{OH})_{2}\right]$ and patient was recalled after 5 days. On subsequent appointment the canal was debrided with $2.5 \%$ sodium hypochlorite and dried with paper points. Colla plug was placed at the site of open apex followed by MTA as apical barrier using plugger until thickness of $5 \mathrm{~mm}$ and a wet cotton pellet was placed over it (FIGURE 3). The access was sealed by temporary filling [as MTA takes 24 hours to set] and patient was called after a week [FIGURE 4].

On subsequent appointment the tempoarary filling was removed and obturation was done using Gutta Percha with lateral compaction technique and post endodontic restoration was done with Composite [FIGURE 5] and the patient was called after 3 days. On next appointment tooth preparation was done and the putty impression was taken and the impression was poured with die stone and cast models were made.Zirconia Crown cementation was done after it was fabricated in the lab. The periapical radiograph was taken after 6 months of treatment which showed no further root resorption. 


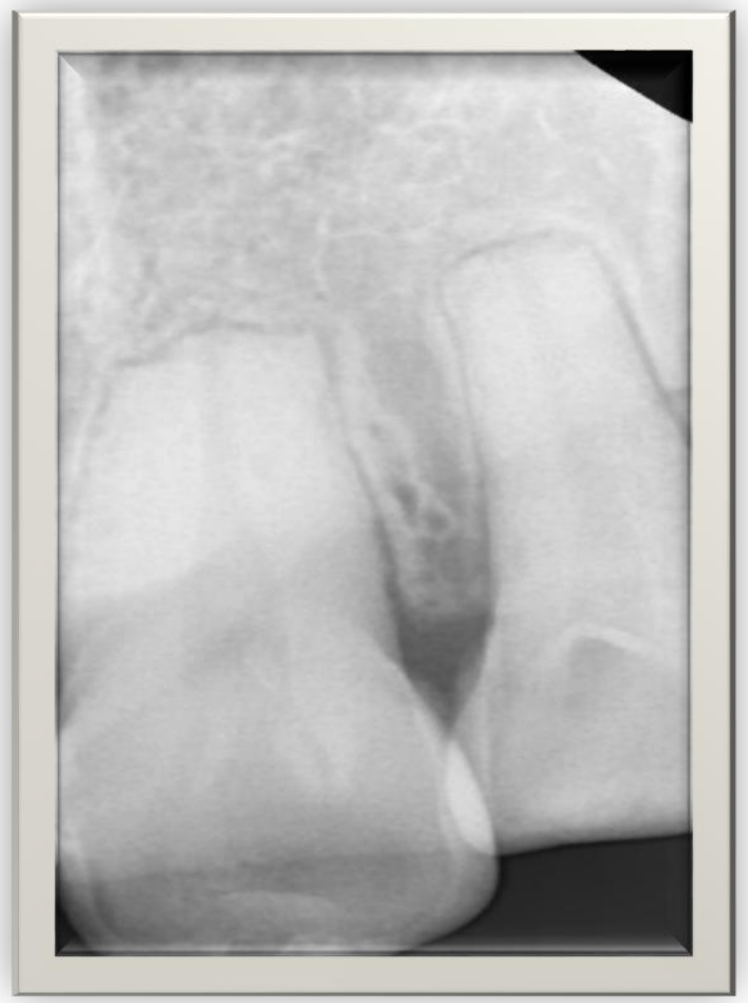

\section{FIG 1: PREOPERATIVE} RADIOGRAPH 


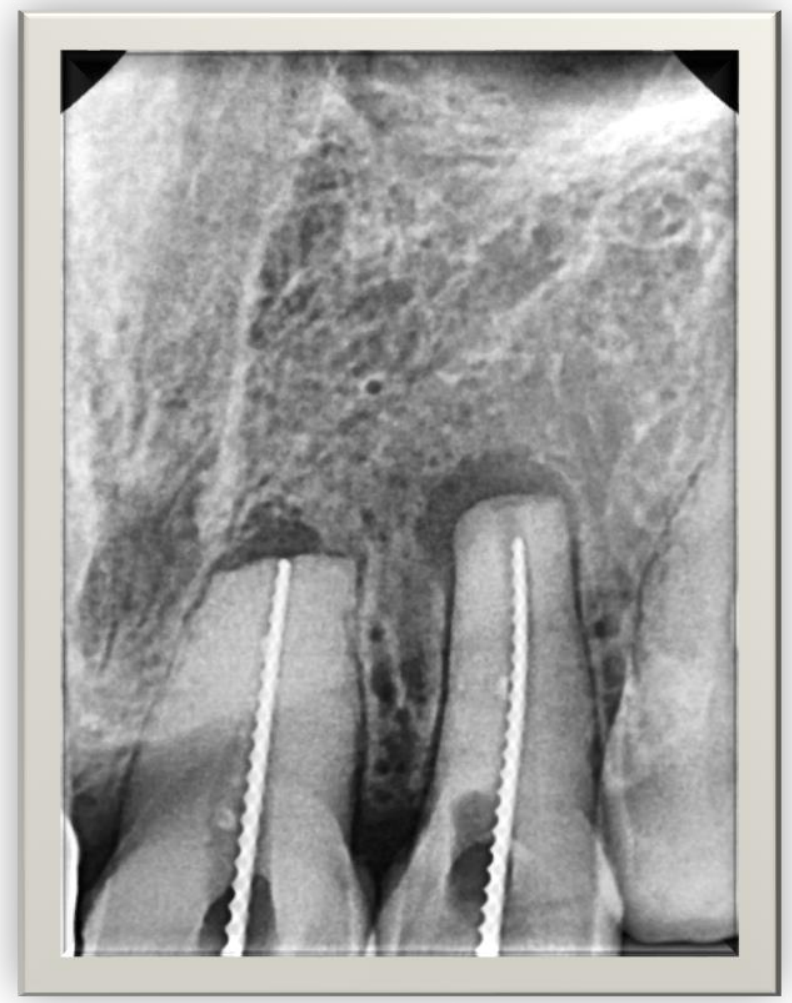

\section{FIG 2: WORKING LENGTH WAS DETERMINED}




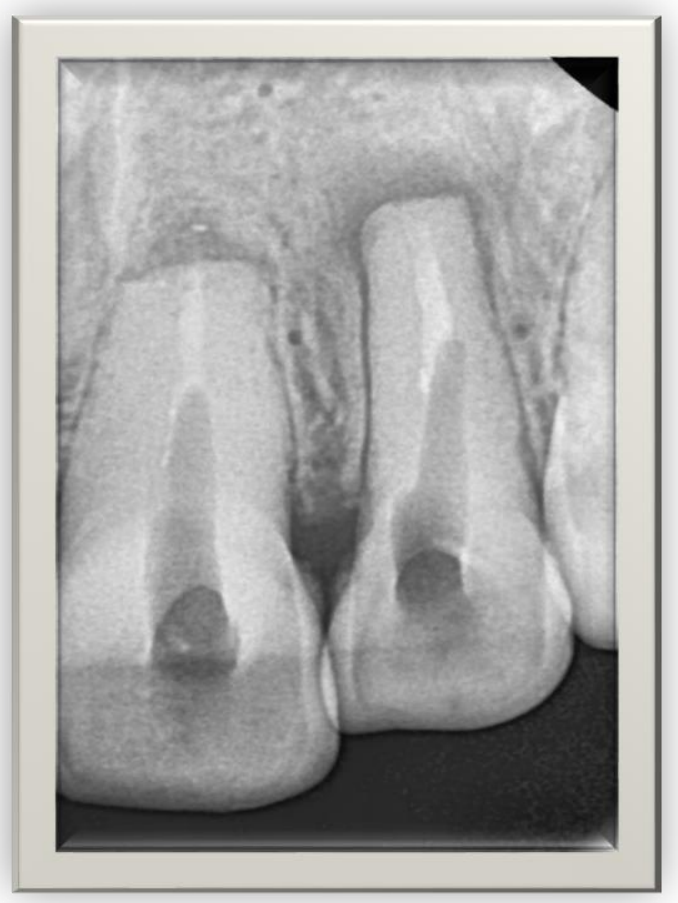

FIG 3 : MTA PLUG FORMATION 


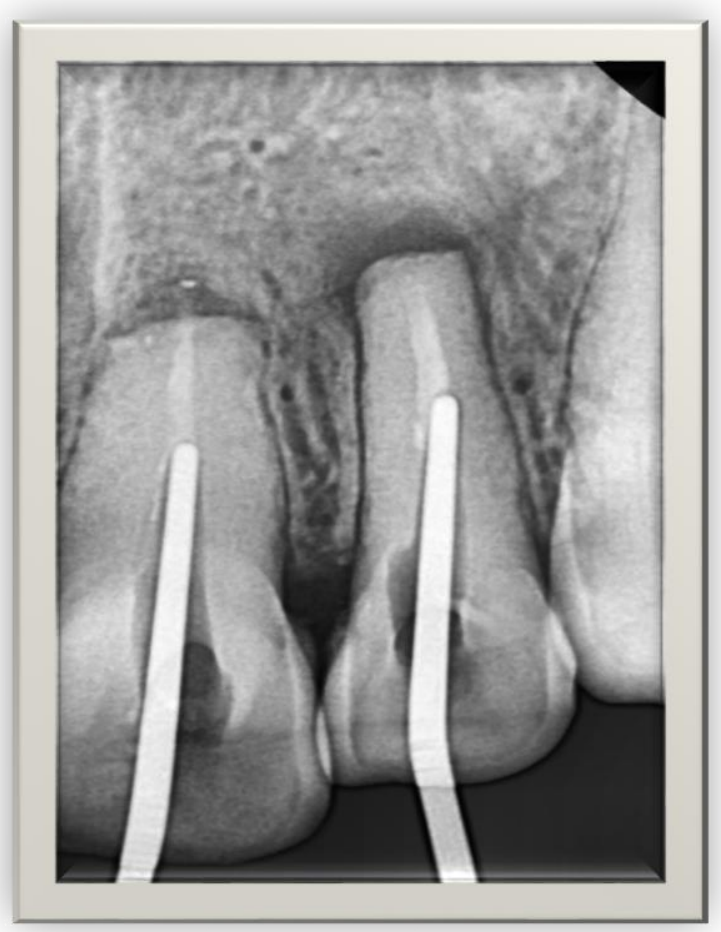

FIG 4: MASTER CONE 


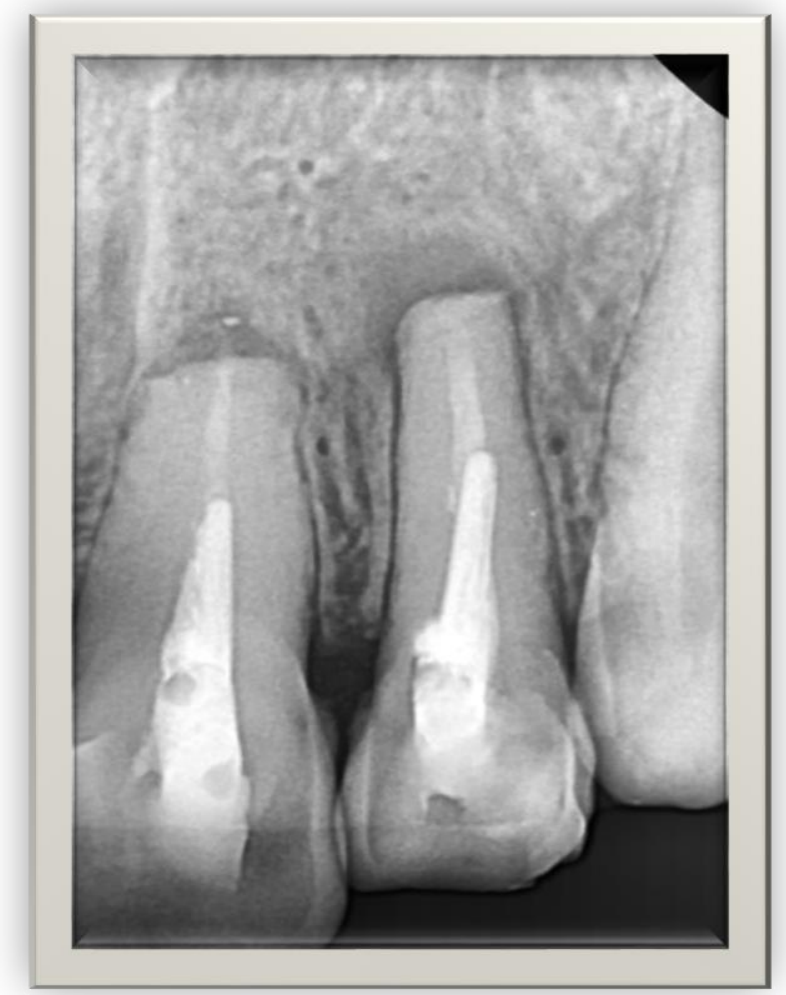

\section{OBTURATION AND POST ENDO DONE}




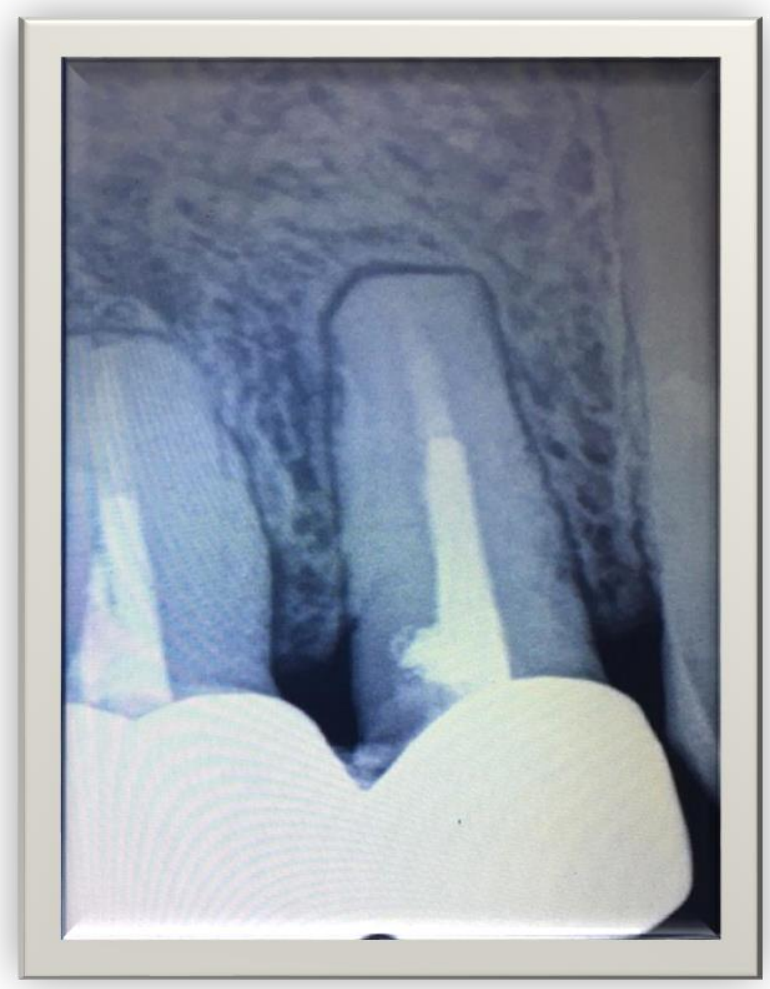

FOLLOW UP AFTER 6 MONTHS 


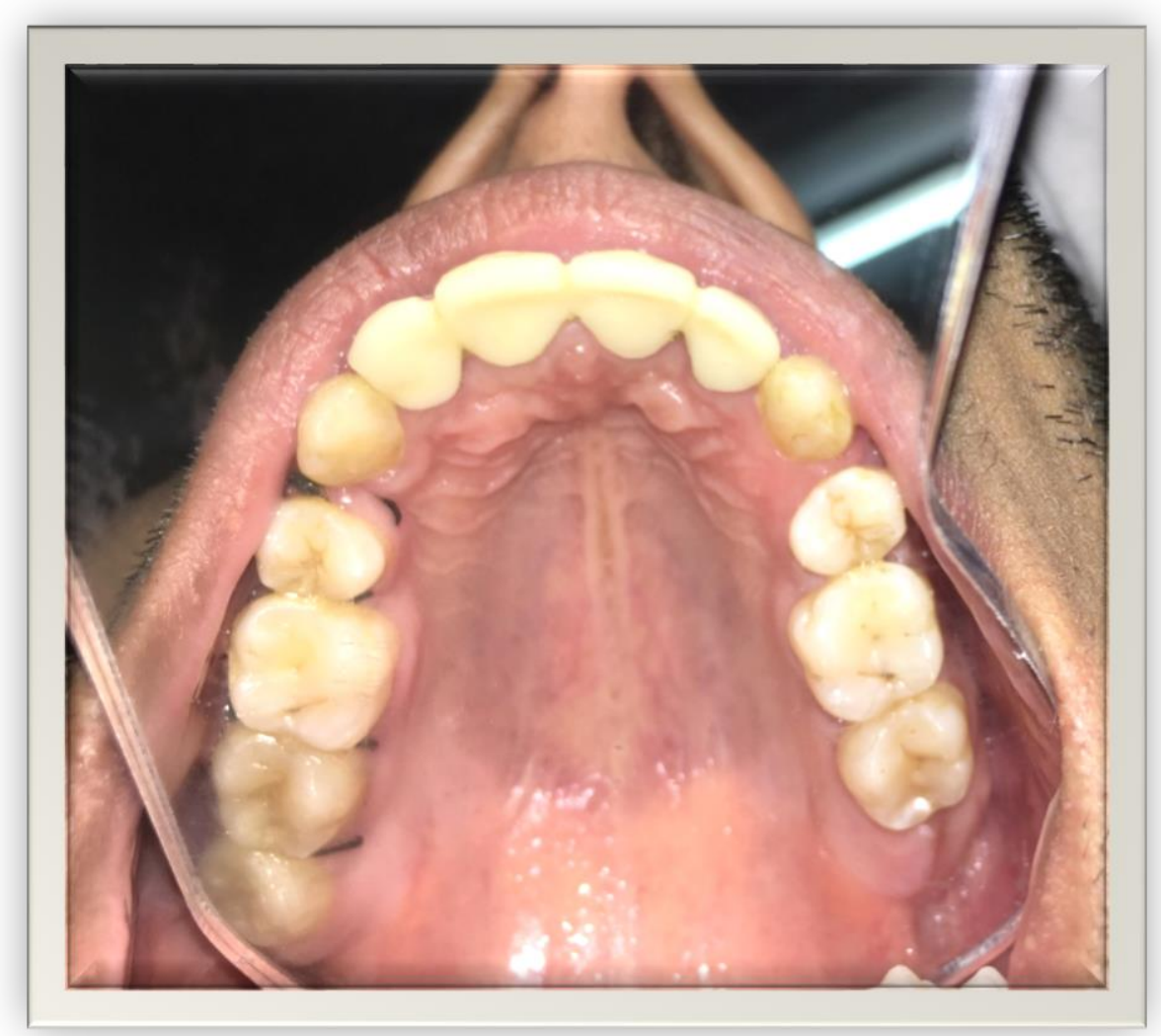

CROWN CEMENTATION-PALATAL VIEW 


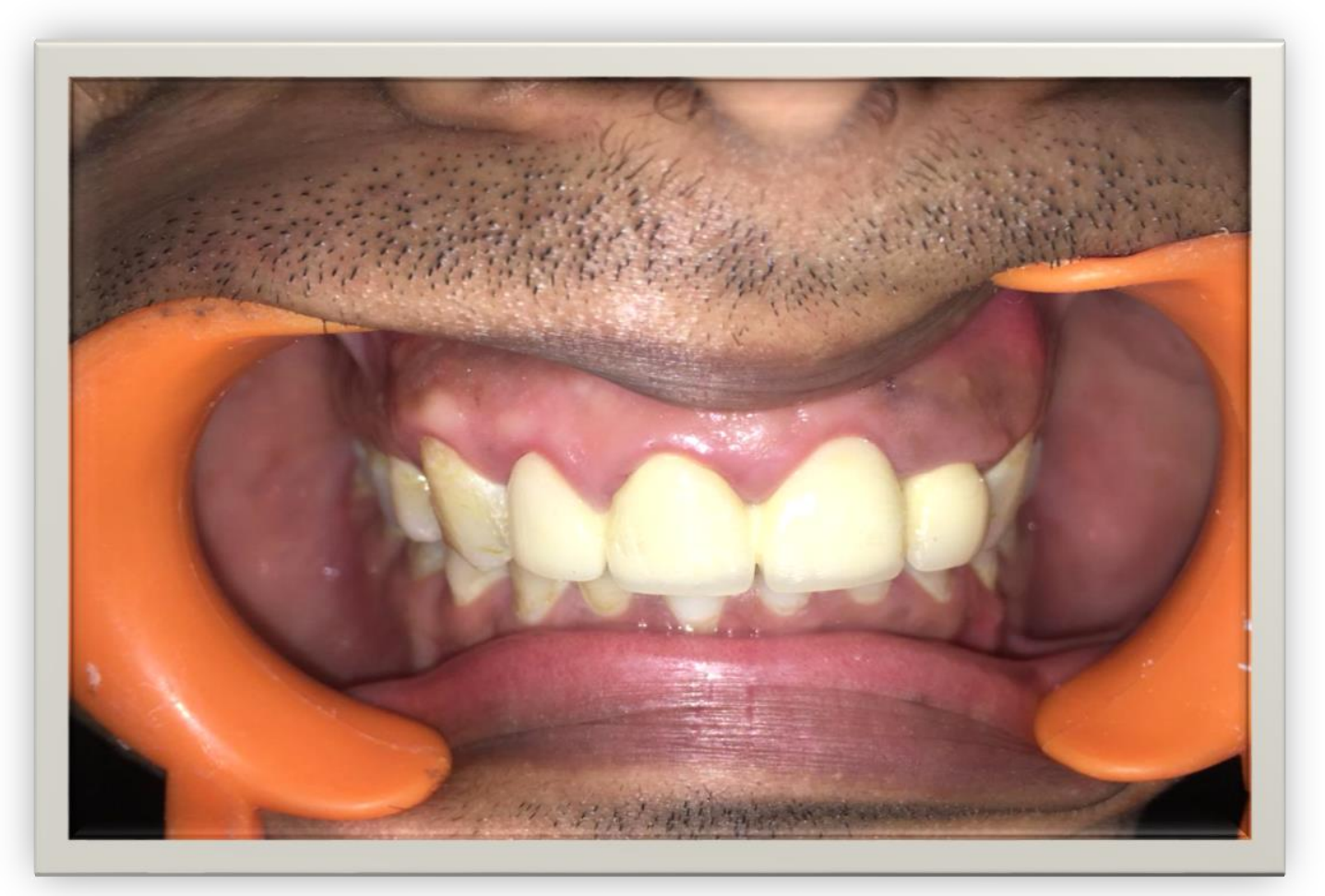

\section{CROWN CEMENTATION- BUCCAL VIEW}

\section{DISCUSSION:}

Dental injuries are very common in children. The type of injuries varies from the tooth fracture to tooth avulsion. The common factor in these injuries is the pulp necrosis. Whenever there is pulp necrosis in an immature tooth,there is interruption in the vascular and nerve supply to the root ${ }^{5}$ and thus the root development gets halted resulting into an open apex and the tooth longevity and stability gets compromised.

To fix this problem, a non surgical procedure is used which is called as Apexification ${ }^{16}$. This is a method which produces an apical barrier in an immature root with open apex and induces the apical development of an incomplete root in a tooth with necrotic pulp ${ }^{15}$.

An apical barrier is mandatory to keep the filling material in place. Previously calcium hydroxide was used and considered as an efficient material for Apexification. Calcium hydroxide has many disadvantages such as it needed many appointments and a long duration procedure so patient compliance was poor.Furthermore if calcium hydroxide was kept for long as apical barrier ${ }^{11}$, it weakened the dentinal walls and so it made tooth fracture more common $^{8}$. The best alternative to calcium hydroxide is MTA and that is mineral trioxide aggregate.
Mineral trioxide aggregate was developed by Torabinejad ${ }^{4}$ and members of Linda University, USA.Initially it was used for root filling materialduring root canal treatment ${ }^{12}$. It is a mixture of Dicalcium silicate,Tricalcium silicate, Tricalcium aluminate, Tetracalcium aluminoferrite and Bismuth oxide.MTA was approved by the US Food and Drug administration for the use in human for the endodontic application in 1998. MTA has good antimicrobial activity ${ }^{14}$ and that is related to its $\mathrm{pH}$ value. Its $\mathrm{pH}$ value is 12.5 in comparison to calcium hydroxide which has $\mathrm{pH}$ 16.The setting time of MTA varies as for Proroot it is 2 hours 50 minutes and for MTA Angelus it is 10 minutes .MTA showed low solubility and it is slightly more radio-opaque than dentine..MTA is used for Apexification, it has many advantages. The first and foremost advantage is the "One visit Apexification "and it is defined as the non surgical condensation of a biocompatible material ${ }^{13}$ into the open apex of an immature root canal. So that an artificial apical barrier is made and now the root filling material is filled to complete the single visit Apexification ${ }^{7}$.MTA has shown good cementing property to amalgam ${ }^{17}$,zincoxide, IRM [intermediate restorative material], eugenol super ethoxybenzoic acid.

In Apexification procedure,MTA acts as a scaffold for the tissue regeneration ${ }^{12}$.It is capable of activation of cementoblasts and helps in laying down of new cementum. It also facilitates 
formation of new PDL and allows bone healing ${ }^{13}$. That is how it relives the patient from his clinicalsymptoms.

Holland et al in 1999 found calcite crystals at the opening of dentinal tubules near to MTAplug. They suggested that the tricalcium oxide in MTA reacts with tissue fluids to form calcium hydroxide that induces dentin bridge formation ${ }^{9}$.The difference from calcium hydroxide is that the formed dentin bridge is faster, its structural integrity is more and is completeand provides a better biologic root cap seal.

Apexification process starts with cleaning and shaping of root canal system, then the MTA is introduced in the apical region through plugger followed by the suitable restoration in the root canal system ${ }^{10}$.The advantages of MTA are short duration treatment,tooth restoration is immediate,it does not harm the mechanical properties of the dentinal walls and so the chances of root fracture is minimal, the healing is faster and complete.

There are few disadvantages of MTA, the prime being is its difficult manipulation and its placement in a wide open apex as there are many chances where it can be extruded into periapical region. Lemon advocated that the dentist should use some matrix material when the diameter of the open apex is more than 1 mm. The matrix material would provide a base over which MTA can be placed at its predictable position. Biodentine ${ }^{15}$ and various matrix materials are available likecalcium sulfate,hydroxyapatite, platelet rich fibrin and colla cote. We have used Collacote inour two cases which is a soft biocompatible sponge obtained from bovine collagen.

First colla cote was placed at open apex and then MTA was condensed against it.The apical matrix Colla Cote used in our patient was user friendly,cost effective and easily available.

\section{CONCLUSION:}

During the last 18 years there have been changes in the rationale governing the treatment of the immature teeth with wide open apex. The dentist should have thorough understanding of the compatibility of the material, its physiological nature, and the histological changes that takes place during and after the use of the material. In present time MTA is a promising material and plays an important role in sealing of root apex ${ }^{8}$ and its further development to a mature root and so it saves the patient from psychological trauma of surgical procedures.

\section{REFERENCES}

[1] Cohen's pathway of the pulp

[2] Ingles endodontics, 6th edition

[3] Mineral Trioxide Aggregate: Properties and clinical Applications: ( MahmoudTorabinejad)
[4] M. Shanmugam, T.S.S Kumar, K.V. Arun, Ramya Arun, S. Jai Karthik(2012): Clinical and histological evaluation of two dressing materials in the healing of palatal wounds

[5] Torabinejad M, Watson TF, Pitt Ford TR. Sealing ability of a mineral trioxide aggregate when used as a root end filling material. J Endod 1993;19:591-5

[6] Felippe WT, Felippe MC, Rocha MJ. The effect of mineral trioxide aggregate on the apexification and periapical healing of teeth with incomplete root formation. Int Endod J 2006;39:2-9

[7] Holden DT, Schwartz SA, Kirkpatrick TC. Clinical outcomes of artificial rootend barriers with mineral trioxide aggregate in teeth with immature apices. J Endod 2008;34:812-7

[8] Sottosanti J. Calcium sulfate: A biodegradable and biocompatible barrier for guided tissue regeneration. Compend Contin Educ Dent 1992;13:226-34

[9] Holland R, Mazuqueli L, Souza V, Murata SS, Dezan E. Influence of the type of vehicle and limit of obturation on apical and periapical tissue response in dogs teeth after root canal filling with mineral trioxide aggregate. J Endod 2017;33:693-7

[10] Broon NJ, Bramante CM, Assis GF, Bortoluzzi EA, Bernardineli N, Moraes IG, et al. Healing of root perforations treated with mineral trioxide aggregate (MTA) and Portland cement. J Appl Oral Sci 2006;14:305-11

[11] Pace, V Giuliani, M Nieri, , Pagavino. Mineral trioxide aggregate as apical plug in teeth with necrotic pulp and immature apices: a 10-year case series. J Endod 2014;40:1250-1254

[12] Koh ET , M Torabinejad, Pittford TR, Brady K. Mineral trioxide aggregate stimulates a biological response in human osteoblasts. Journal of Biomedical Materials Research 1997;37:432-39

[13] Sipert CR, Hussne RP, Nishiyama,Torres SA . In vitro antimicrobial activity of Fill Canal, Sealapex, Mineral Trioxide Aggregate, Portland cement and EndoRez, Int Endod J 2009; 38: 539-43

[14] Kubasad GC, Ghivari SB. Apexification withapical plug of MTA-report of cases. Arch Oral SciRes.2011; 1(2):104-7.

[15] Torabinejad M, Dean J. Tooth filling material and method of use. United State Patent No. 5,415,547, USA.Loma Linda University.

[16] Torabinejad M, Ford TR, Abedi HR, Kariyawasam SP, Tang HM . Tissue reaction to implanted

[17] root-end filling materials in thetibia and mandible of guinea pigs. JOE 2016;24: 468-71

[18] Koh ET, McDonald F, Pitt Ford TR, Torabinejad M. Cellular response to mineral trioxide aggregate. J Endod 1998;24:543-7

[19] Andreasen JO, Farik B, Munksgaard EC. Long-term calcium hydroxide as a root canal dressing may increase risk of root fracture. Dent Traumatol 2002;18:134-7.

\section{AUTHORS}

First Author - Dr.Tanu Mahajan, M.D.S. 3RD Year student, Department of Conservative Dentistry and Endodontics, ITS Dental College,Hospital\& Research Centre,Greater Noida Delhi NCR,Phone number +919837206943

Email I.D. drindumahajan@yahoo.co.in

Tanu Mahajan tanumahajan_mds17_20_gn@its.edu.in

Second Author - Dr.ROHIT KOCHHAR B.D.S.,M.D.S.

H.O.D. Department of conservative and endodontics ITS Dental College,Hospital\& Research Centre ,Greater Noida Delhi NCR,

Third Author - Dr.Manju Kumari B.D.S. , M.D.S. Professor Department of Conservative Dentistry and Endodontics,

ITS Dental College,Hospital\& Research Centre ,Greater Noida Delhi NCR, 
